\title{
A Design of MIMO System Based on Y-Shaped with QSCS for UWB Applications
}

\author{
Nada M. Khalil Al-Ani †, Oras A. Shareef Al-Ani and Mahmood F. Mosleh \\ Computer Engineering Techniques Middle Technique University Baghdad, Iraq \\ E-mail: \{eng.nada1985, oras.a.s.alani\}@gmail.com; drmahfa@yahoo.com \\ Read A. Abd-Alhameed \\ School of Engineering and Informatics University of Bradford Bradford, Uk \\ E-mail: r.a.a.abd@bradford.ac.uk
}

Received: 28 October 2019; Accepted: 20 December 2019; Published: 08 February 2020

\begin{abstract}
The multi-path fading environment is a major challenge of UWB devices. So, a MIMO system is one of the importance techniques which exploited to mitigate such problems. In this research, a MIMO system with eight ports consists of four antenna elements has proposed. Y-shaped of patch microstrip has chosen to design each element to enhance the bandwidth of the proposed system. In order to achieve a good isolation, the geometry of the ground layer of the proposed antenna element has based on quasi-self-complementary structure. The proposed model has a compact size because it facilitates with dual polarized ports which increase the capacity and maintaining an acceptable size. The results are show that a bandwidth of $2.06 \mathrm{GHz}$ has obtained with operating frequency of $8.73 \mathrm{GHz}$ for single elements and the integrated MIMO system when excited simultaneously.
\end{abstract}

Index Terms-QSCS, Dual polarized ports, Y-shaped of microstrip, MIMO, VSWR.

\section{INTRODUCTION}

Recently, wireless communication system studied the Ultra-Wide Band (UWB) extensively, due to its high rate of data transmission, low-cost and low transmitted power. However, UWB has the multipath fading problem which require high complexity at receiver end. Multiple Input Multiple Output (MIMO) technology has been proposed to address this problem. In addition, MIMO system has an efficient property can be employed to improve UWB system which is achieving an efficient spectrum and mitigating multipath problem [1]. The combination of these two technologies have been improve an enhancement of communications with short ranges to operate at very low power levels [1]. However, the main challenges for the MIMO antenna engineering design is to achieve low profile antenna and the ability to eliminate the mutual coupling between neighboring ports of MIMO group [2]. There is a polarization diversity to evolve the antenna capacity with compact design [3]. Also, the polarization is favored the patch microstrip antenna design to improve MIMO profile in term of small size, light weight, easy to fabricate and high efficiency [4]. However, the microstrip antenna suffer from narrow frequency bandwidth which can be improved by mainly techniques; theory of the circuit and structural [5]. A lot of researches deal with modifying the microstrip structure such as in [6], design a dual port of Y-shaped microstrip antenna to achieve a wide matching impedance of bandwidth. Also, [3] used a fractal microstrip antenna to achieve low operating frequency point. On the other hand, [7-8] proposed Y and F- shaped of microstrip antenna respectively to increase bandwidth frequency with a suitable efficiency. Because of limited space systems, UWB go to miniaturization technique antennas $[9,10]$. In order to mitigate the mutual coupling between adjacent ports, Quasi-Self-Complementary Structure (QSCS) antenna has been potential enormously applied. QSCS means etching the ground layer with complemented shape to the patch layer [11]. The benefits of such structure are investigating a widen bandwidth such as in [12], degrade the efficient of radiation, the input impedance is constant with a variable frequency issue, easily impedance matching for the wide band and can achieve high isolation between polarized ports without any parasitic structure $[11,13]$. In $[11,15]$ structures based on QSCS which obtained high isolation of MIMO diversity system antenna for UWB application, But the first one proposed a patch design of half fan shaped with polarized diversity and the other one having a patch based half circle with spatial diversity. Because of the size reduction is still one of the main challenges for future applications, in this research, a proposed of a MIMO antenna system concerned with polarization diversity, conversely [6] which applied spatial diversity. Also, the proposal having a patch microstrips ended in Yshaped as a radiator. To achieve isolation, QSCS is applied achieving high isolation with UWB that would be matching the required facilities of future wireless communication especially in term of size reduction by utilizing dual polarization technique. 


\section{The Proposal of Mimo Antenna System}

In order to propose a polarized MIMO antenna system, it must firstly propose a single antenna paradigm and ensure it operate perfectly. Fig. 1 shows the single antenna element which consists of three layers. The first one is the patch layer constructed from dual polarized microstrip resistances each of $50 \Omega$, Y-shaped connected by SMA as a connector which installed over a ground layer etched with QSCS. Patch and ground layers are separated by dielectric layer of $1.6 \mathrm{~mm}$ height made of Rogers RO3003(lossy) with permittivity 3 and thermal conductivity 0.001 . The dimensions of such antenna detailed in Table1.

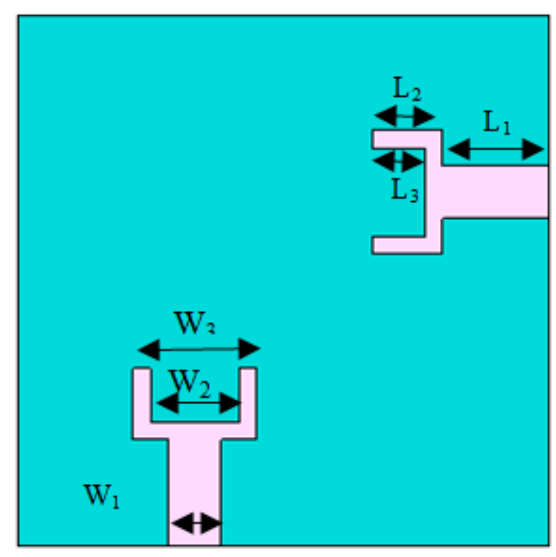

(a)
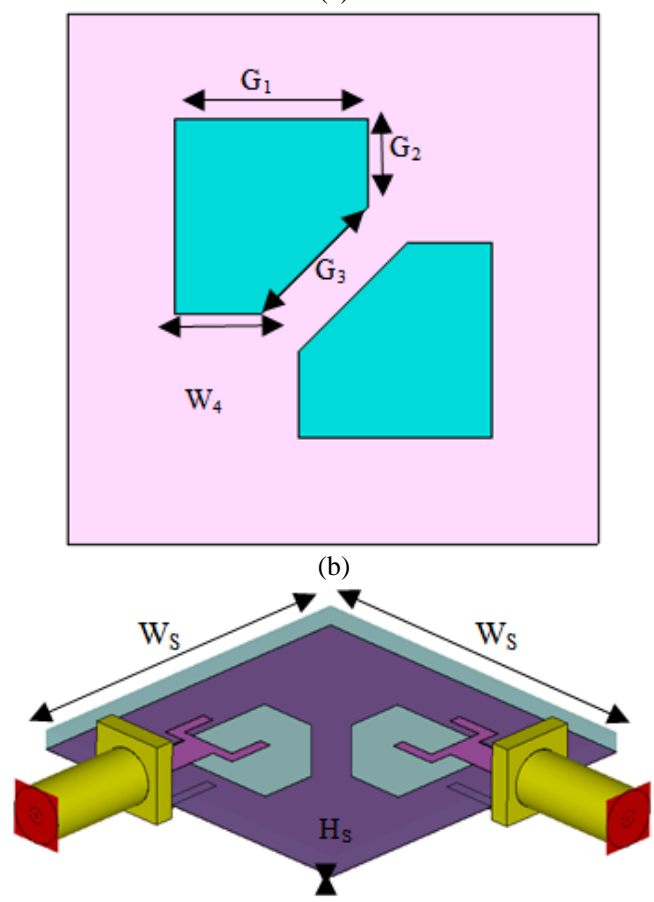

(c)

Fig.1. Single antenna element: (a) Front View, (b) Back View, and (c) Side View.
Table 1. Single antenna element dimension values.

\begin{tabular}{|c|c|c|c|c|c|}
\hline No. & Parameter & $\begin{array}{c}\text { Value } \\
(\mathrm{mm})\end{array}$ & No. & Parameter & $\begin{array}{c}\text { Value } \\
(\mathrm{mm})\end{array}$ \\
\hline 1 & $\mathrm{~W}_{\mathrm{S}}$ & 30 & 7 & $\mathrm{~L}_{2}$ & 4 \\
\hline 2 & $\mathrm{~W}_{1}$ & 3 & 8 & $\mathrm{~L}_{3}$ & 3 \\
\hline 3 & $\mathrm{~W}_{2}$ & 5 & 9 & $\mathrm{G}_{1}$ & 11 \\
\hline 4 & $\mathrm{~W}_{3}$ & 7 & 10 & $\mathrm{G}_{2}$ & 4.88 \\
\hline 5 & $\mathrm{~W}_{4}$ & 8.66 & 11 & $\mathrm{G}_{3}$ & 8.66 \\
\hline 6 & $\mathrm{~L}_{1}$ & 6 & 12 & $\mathrm{H}_{\mathrm{S}}$ & 1.6 \\
\hline
\end{tabular}

Four replicas of such single antenna which proposed are integrated on a printed circuit board (PCB) which consists of dielectric layer as that of single element with a dimension of $79 \times 150 \mathrm{~mm}^{2}$ which is desirable size for future application and consider the most contribution of this paper as shown in Fig.2. The distances separated between each four elements are represented the extended ground layer for each one.

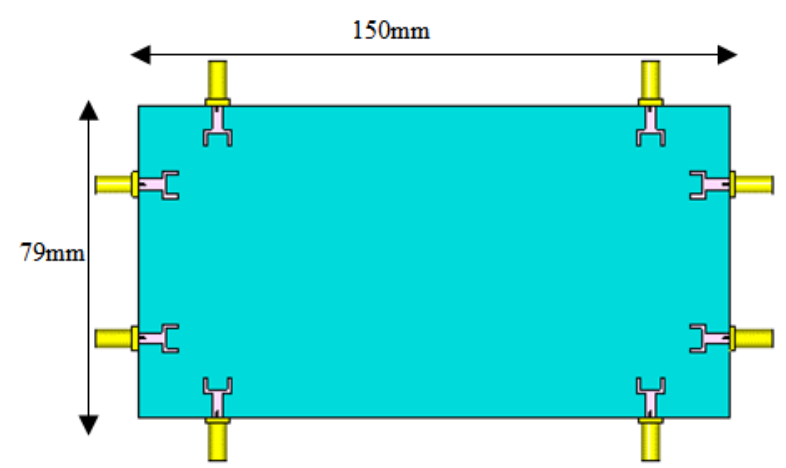

(a)

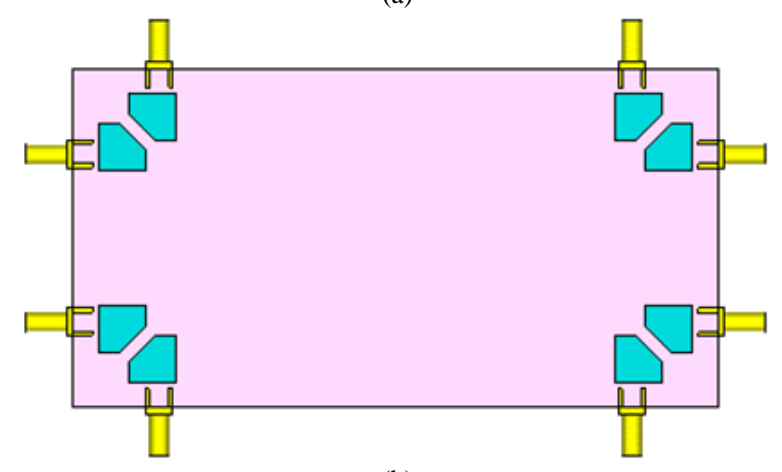

(b)

Fig.2. MIMO antenna system: (a) Front View and (b) Back View.

\section{RESULTS AND DISCUSSIONS}

The proposed single antenna and the MIMO group are simulated using CST-STUDIO 2019 to show its performance. After running the simulated design of single element, Fig. 3 (a) exhibits the S-Parameter of the single element. The resultant of the operating frequency 
was $8.73 \mathrm{GHz}$ with $-53 \mathrm{~dB}$ of return losses and bandwidth of $2.06 \mathrm{GHz}(8.13-10.19) \mathrm{GHz}$ at $-10 \mathrm{~dB}$. Also, high isolation can be achieved over all the band (3.1-10.5) GHz. According to [4] which indicated that, the antenna performance must be not exceed $2 \mathrm{~dB}$. As illustrated from Fig. 3 (b), the VSWR of the proposed antenna approach $1 \mathrm{~dB}$ at resonance frequency which is satisfy VSWR condition.

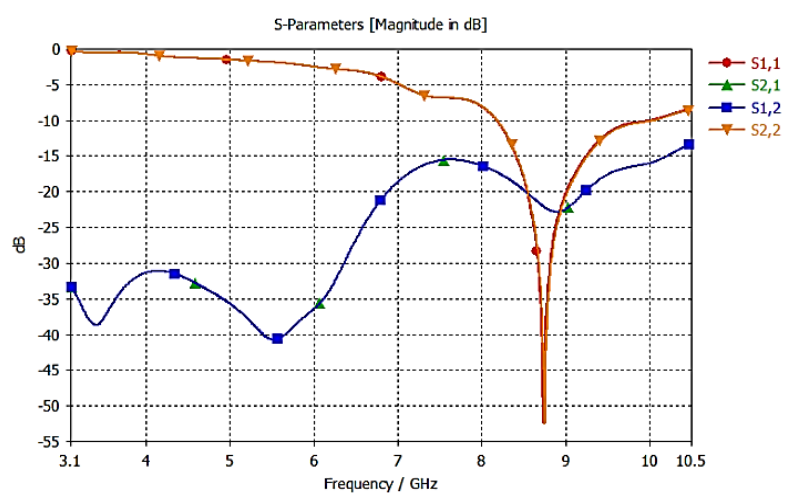

(a)

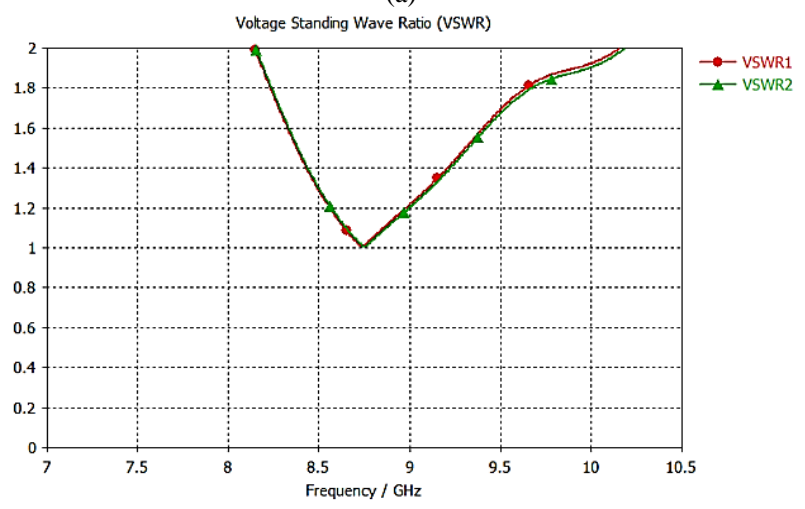

(b)

Fig.3. Results of single antenna: (a) S-Parameter and (b) VSWR.

On the term of radiation pattern, Fig. 4 exhibit the 2D polar pattern for each port it obviously shown similar with lobe has angular width of $73.5 \mathrm{deg}$. While the 3D pattern with both ports simultaneously obtain a coverage area having $\mathrm{H}$-max of $-29 \mathrm{~dB}$ and gain of $4.66 \mathrm{dBi}$.

Farfied $H$-Field $(r=1 m)$ Abs (Phi=90)

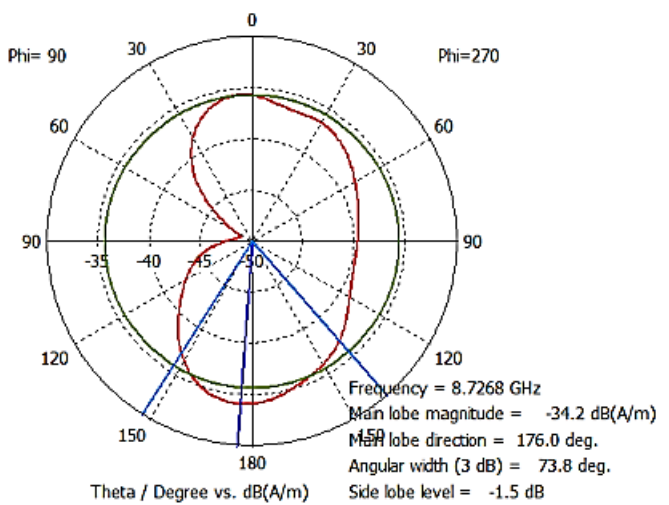

(a)
Farfield H-Field $(r=1 \mathrm{~m})$ Abs (Phi=0)

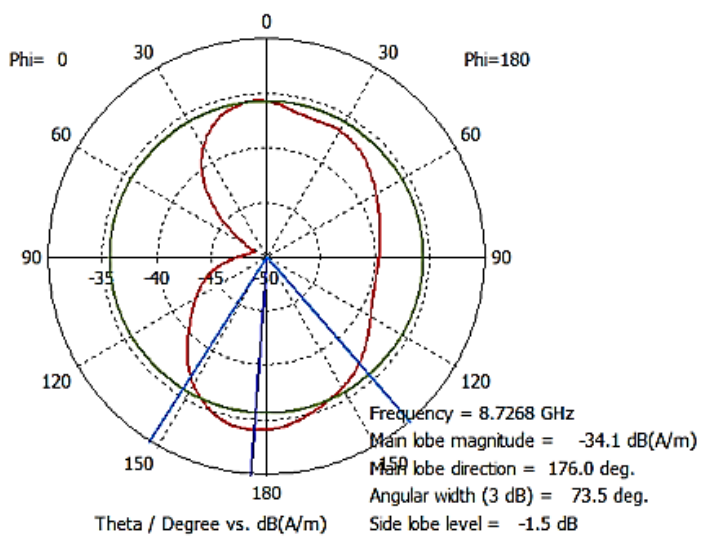

(b)

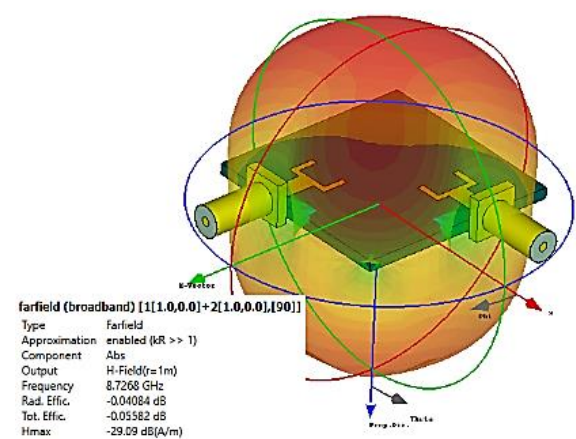

(c)

Fig.4. Radiation Pattern of Single Antenna Element: (a), (B) 2D OF Port1 and 2 respectively, and (c) 3D for both ports.

Accordingly, the performance of integrated MIMO system with 8 ports show that all elements operate on a same resonance frequency of $8.73 \mathrm{GHz}$ with bandwidth of $2.06 \mathrm{GHz}$ which is match the single antenna resonance frequency and bandwidth respectively. As illustrated in Fig. 5 (a), the result show that there are a slightly difference between the response curve of each opposite ports. Such differences stimulate from current surface of the PCB and can be achieved a return loss of one group $20 \mathrm{~dB}$ and $-33 \mathrm{~dB}$ of other. Also, Fig.5 (b) shows the mutual coupling under $-20 \mathrm{~dB}$ for all ports when excited simultaneously, while Fig.5 (c) exhibits a desired VSWR which investigate the condition of it.

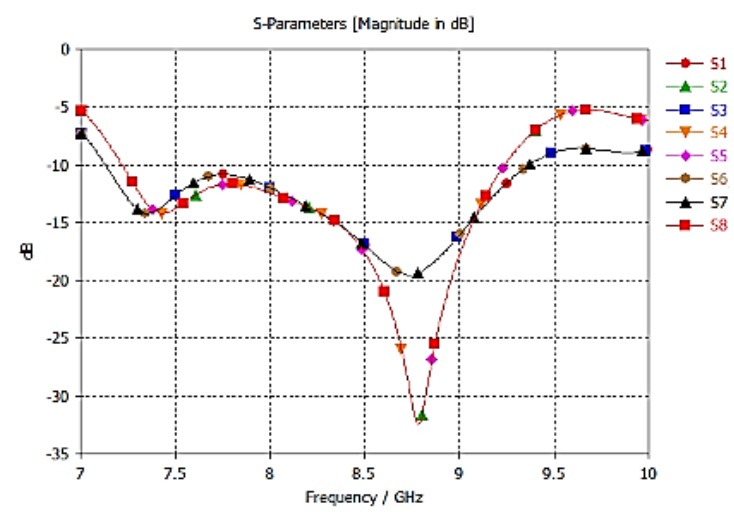

(a) 


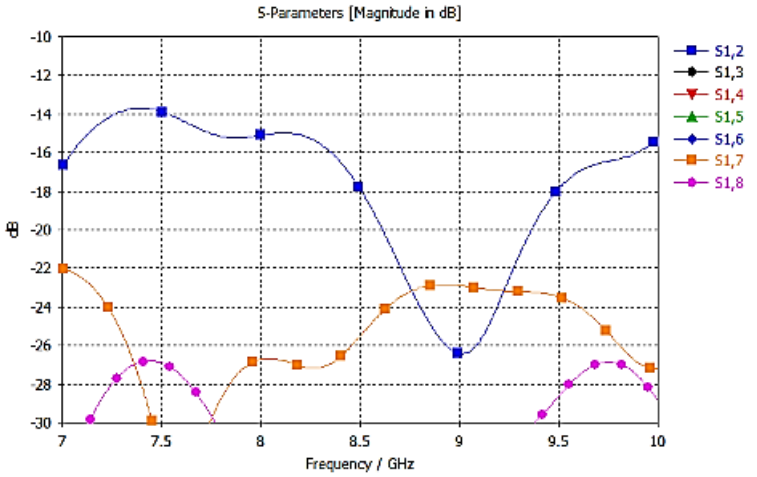

(b)

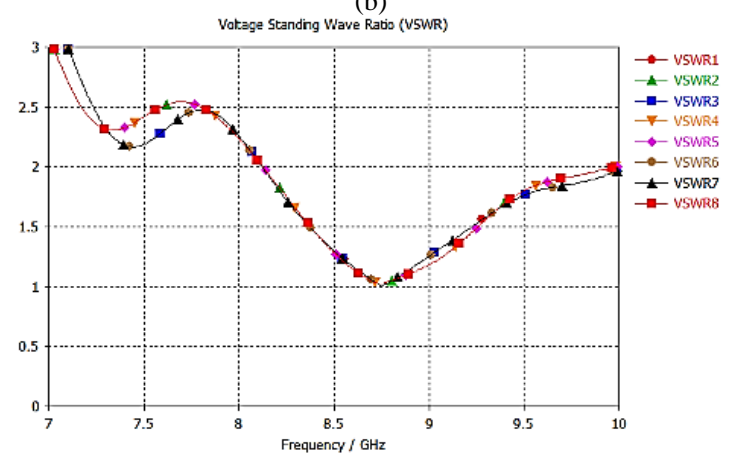

(c)

Fig.5. MIMO Antenna System: (a) S-Parameter, (B) Mutua Coupling, and (c) VSWR

Furthermore, Fig.6 illustrated the radiation pattern for all ports which appears omnidirectional in 2D polar pattern with lobe having angular width of 173 degree, while the 3D patterns shows the full coverage of the system device with H-max $-19.9 \mathrm{~dB}$ and a gain of $7.82 \mathrm{dBi}$.

From previous results, it is obliviously the proposed model is obtained an acceptable bandwidth and gain which match the UWB frequency ranges as well as a perfect isolation obtained which avoiding the effects of current surface. Note, because of the large data, the data acquisition of all result's figures can't be listed. Also, such results are exported from CST-STUDIO 2019 then it can be plotted with EXCELL or MATLAB package.

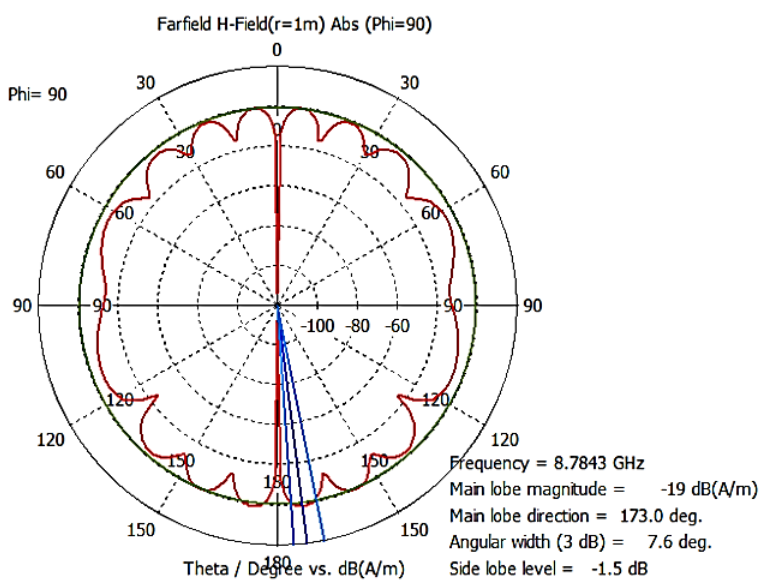

(a)

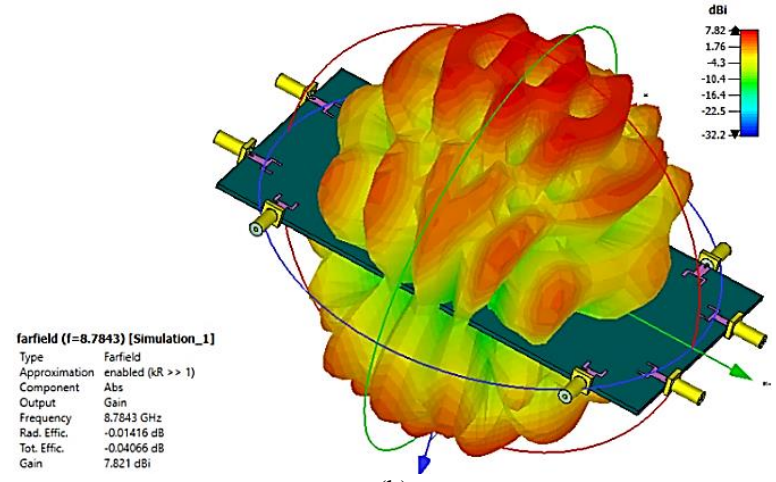

(b)

Fig.6. Radiation Pattern of MIMO Antenna System: (a)2D, and (b) 3D.

\section{CONCLUSION}

In order to design MIMO antenna system match UWB system conditions, this research present four antenna elements each with dual polarized ports. Such elements installed on a corners of one PCB incorporating together aiming to propose a MIMO system concerned with polarization as well as spatial diversity and minimize system size as can as possible. Also, the proposal deals with rectangular patch microstrip feeding lines ended with Y-shaped to increase the operating bandwidth. Furthermore, QSCS is used to mitigate the mutual coupling and contribute the bandwidth enhancement.

\section{REFRENCES}

[1] See, T S P, and Chen, Z N. An Ultra-wideband diversity antenna. IEEE Trans. Antennas Propag, 2009, 57(9): 1597-1605

[2] Mohammad S Sharawi. Printed MIMO Antenna Engineering. Artech House,2014, available on the site https://books.google.iq/books?hl=ar\&lr=\&id=7INTBAA AQBAJ\&oi=fnd\&pg=PR1\&dq=Mohammad+S+Sharawi, +Printed+MIMO+Antenna+Engineering.+Artech+House, 2014.\&ots=aGEFL_E1W1\&sig=b-

nh54cw0bkfDwVOJgGuEZupCl4\&redir_esc=y\#v=onepa ge\&q=Mohammad $\% 20 \mathrm{~S} \% 20$ Sharawi $\% 2 \mathrm{C} \% 20$ Printed $\% 2$ 0MIMO\%20Antenna\%20Engineering.\%20Artech\%20Ho use \%2C2014.\&f=false. Visited on 1 Oct. 2019.

[3] Queen of Mary. Antenna Designs for MIMO Systems. University of London, HMSO, 2004, available on the site:http://physics.oregonstate.edu/ hetheriw/astro/rt/info/ rf_antennas/antenna_designs_mimo.pdf. Visited on 4 Nov. 2019.

[4] Mohammed Aboud Kadim, Mahmoud F. Moslah, Shereen Abdalkadum Shandal, Yaqeen Sabah Mezaal. New Compact Wideband Microstrip Antenna for Wireless Applications. Advanced Electromegnatic. 2018, 7 (4): 8592.

[5] Prof. Neenansha Jain and Shikha Verma. Survey on Different Shape Microstrip Antenna with Different Slots. IJSRD - International Journal for Scientific Research \& Development. 2017, 5 (9): 2321-0613.

[6] Seokjin Hong, Kyungho Chung, Jaewon Lee, Sangwook Jung, Sang-Sun Lee, and Jaehoon Choi. Design of A Diversity with Stubs for UWB Applications. Microwave and Optical Technology Letters. 2008, 50 (5). 
[7] Naresh Kumar Joshi and Pawan Arunkumar Upadhye. Yshaped Microstrip Patch Antenna. International Conference on Micro-Electronics and Telecommunication Engineering. 2016.

[8] Amit A. Deshmukh, Shefali Pawar, Amita Mhatre and Vivek Chaudhary. Design of Compact F-shape Microstrip Antenna For Dual Polarized Broadband Response," Procedia Computer Science. 2018, 143: 80-86.

[9] L Guo, Z Yang, J Liang, X Chen, and C G Parini. An Improved Design of Orthogonal Half Disc UWB Antenna. Proc. EuCAP, Nice, France. 2006: 6-10.

[10] Z Chen, T See, and X Qing. Small Printed Ultrawideband Antenna with Reduced Ground Plane Effect. IEEE Trans. Antennas Propag. 2007, 55 (2): 383-388.

[11] Xu, P, Fujimoto, K., and Lin, S. Performance of Quasi Self Complementary Antenna Using a Monopole and a Slot. IEEE Antennas and Propagation Society Int. Symp., San Antonio, TX, USA, 2002.

[12] Lu Guo, Sheng Wang, Xiaodong Chen and Clive Parini. A Small Printed Quasi-Self-Complementary Antenna for Ultrawideband Systems. IEEE Antennas and Wireless Propagation Letters. 2009, 8:554-559.

[13] Jianfeng Zhu, Shufang Li, Botao Feng, Li Deng, and Sixing Yin. Compact Dual Polarized UWB Quasi-SelfComplementary MIMO/Diversity Antenna with BandRejection Capability. IEEE Antennas and Wireless Propagation Letters. 2015, 15: 905 - 908.

[14] Velusamy Bhanumathi and Govindarajan Sivaranjani. High Isolation MIMO Antenna Using Semi-Circle Patch for UWB Applications. Progress in Electromagnetics Research C. 2019, 92: 31-40.

[15] Mohammed Aboud Kadim, Mahmoud F Moslah, Shereen Abdalkadum Shandal, Yaqeen Sabah Mezaal. New Compact Wideband Microstrip Antenna for Wireless Applications. Advanced Electromegnatic. 2018, 7 (4): 8592.

\section{Authors' Profiles}

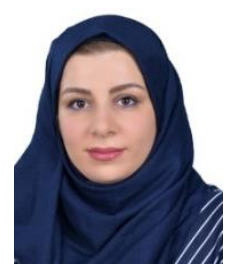

Nada M. Khalil al-Ani was born in Iraq on Aug. 26, 1985. She received her B.Sc. in Computer Engineering Techniques (CET), Middle Technical University, Baghdad Iraq, in 2007. She worked as an employment in the Baghdad Governorate Office since 2008. She is currently pursuing to get MSc. Degree in CET. Her reasearch include, Multi Element Dual-Polarized MIMO Slot Antenna System for 5G Smartphone Applications.

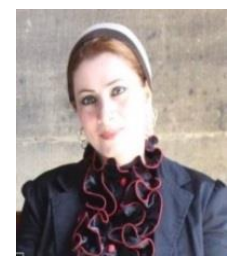

Oras A. Al-Ani received the B.Sc and M.Sc degrees in Laser and Optoelectronic Engineering from AlNahreen University, Iraq, in 2000 and 2002, respectively, and $\mathrm{PhD}$ in Nanomaterial-based solar cell from Newcastle University, UK. She is officially represented Newcastle University students at the NUS National Conference (19-21 April 2016 in Brighton) as elected self-defining woman delegate. Dr Al-Ani is a member of IEEE, IET and Al-Kindi Society for Engineers; and awarded several awards for the best paper and presentation. Oras served as the Event
Coordinator for the Annual Research Conference at Newcastle University and she acted as the School Representative of research student's in Newcastle University

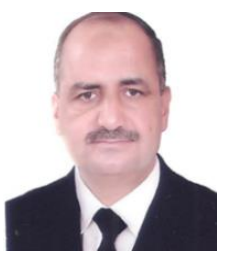

Mahmood F. Mosleh received a Diploma degree from the institute of Technology/ Baghdad in 1978 in the field of electronic Technique; he worked in the same institute up to 1992 as a Technical Trainer. He the B.Sc., M.Sc. and Ph.D. degrees from University of Technology in 1996, 1999 and 2008 respectively. Through those periods and up to now, he worked as advanced Trainer, Assistance Lecturer, Lecturer, Assistance Professor and Professor in the Electrical Engineering Technical College/ Baghdad. $\mathrm{He}$ published about 40 papers in various Journals in the field of Communications Engineering. He has a patent in designing a palm climber robot. He supervised $11 \mathrm{M}$. Sc. And 2 Ph.D. students. Currently he is the Chairman of the Iraqi international Electro-technical Committee.

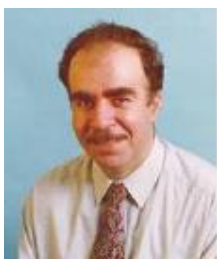

Raed Abd-Alhameed (M'02, SM'13) received the B.Sc. and M.Sc. degrees from Basrah University, Basrah, Iraq, in 1982 and 1985, respectively, and the Ph.D. degree from the University of Bradford, West Yorkshire, U.K., in 1997, all in electrical engineering. He is Professor of Electromagnetic and Radio Frequency Engineering at the University of Bradford, UK. He has long years' research experience in the areas of Radio Frequency, Signal Processing, propagations, antennas and electromagnetic computational techniques, and has published over 500 academic journal and conference papers; in addition, he is co-authors of three books and several book chapters. At the present he is the leader of Radio Frequency, Propagation, sensor design and Signal Processing; in addition to leading the Communications research group for years within the School of Engineering and Informatics, Bradford University, UK. He is Principal Investigator for several funded applications to EPSRCs and leader of several successful knowledge Transfer Programmes such as with Arris 0278-0046 (c) 2016 IEEE. Personal use is permitted, but republication/redistribution requires IEEE permission. See

http://www.ieee.org/publications_standards/publications/ rights/index.html for more information. This article has been accepted for publication in a future issue of this journal, but has not been fully edited. Content may change prior to final publication. Citation information: DOI 10.1109/TIE.2017.2719602, IEEE Transactions on Industrial Electronics IEEE TRANSACTIONS ON INDUSTRIAL ELECTRONICS (previously known as Pace plc), Yorkshire Water plc, Harvard Engineering plc, IETG Itd, Seven Technologies Group, Emkay ltd, and Two World ltd. He has also been a co-investigator in several funded research projects including: 1) H2020 MARIE Skłodowska-CURIE ACTIONS: Innovative Training Networks (ITN) "Secure Network Coding for Next Generation Mobile Small Cells 5G-US", 2) Nonlinear and demodulation mechanisms in biological 
tissue (Dept. of Health, Mobile Telecommunications \& Health Research Programme and 3) Assessment of the Potential Direct Effects of Cellular Phones on the Nervous System (EU: collaboration with 6 other major research organizations across Europe). He was awarded the business Innovation Award for his successful KTP with Pace and Datong companies on the design and implementation of MIMO sensor systems and antenna array design for service localizations. He is the chair of several successful workshops on Energy Efficient and Reconfigurable Transceivers (EERT): Approach towards Energy Conservation and $\mathrm{CO} 2$ Reduction that addresses the biggest challenges for the future wireless systems. He has also appointed as guest editor for the IET Science, Measurements and Technology Journal since 2009, and 2012. He is also a research visitor for Wrexham University, Wales since Sept 2009 covering the wireless and communications research areas. His interest in computational methods and optimizations, wireless and Mobile communications, sensor design, EMC, beam steering antennas, Energy efficient PAs, RF predistorter design applications. He is the Fellow of the Institution of Engineering and Technology, Fellow of Higher Education Academy and a Chartered Engineer.

How to cite this paper: Nada M. Khalil Al-Ani, Oras A. Shareef Al-Ani, Mahmood F. Mosleh, Read A. AbdAlhameed, "A Design of MIMO System Based on YShaped with QSCS for UWB Applications", International Journal of Information Technology and Computer Science(IJITCS), Vol.12, No.1, pp.17-23, 2020. DOI: 10.5815/ijitcs.2020.01.03

\section{APPENDIX A}

\begin{tabular}{|c|c|c|c|c|c|}
\hline Frequency / GHz & $\mathrm{S} 1,1 / \mathrm{abs}, \mathrm{dB}$ & Frequency / GHz & $\mathrm{S} 1,1 / \mathrm{abs}, \mathrm{dB}$ & Frequency / GHz & $\mathrm{S} 1,1 / \mathrm{abs}, \mathrm{dB}$ \\
\hline & & 7.3476 & -6.6230195 & & \\
\hline 7.0071998 & -4.9332621 & 7.355 & -6.6436427 & 7.6954002 & -6.9438974 \\
\hline 7.0145998 & -4.9756426 & 7.3624001 & -6.6633005 & 7.7027998 & -6.9502604 \\
\hline 7.0219998 & -5.0182109 & 7.3698001 & -6.6819987 & 7.7101998 & -6.9572725 \\
\hline 7.0293999 & -5.0609408 & 7.3772001 & -6.6997414 & 7.7175999 & -6.9649692 \\
\hline 7.0367999 & -5.1038076 & 7.3846002 & -6.716539 & 7.7249999 & -6.9733871 \\
\hline 7.0441999 & -5.1467823 & 7.3920002 & -6.7324013 & 7.7323999 & -6.9825617 \\
\hline 7.0516 & -5.1898406 & 7.3994002 & -6.7473426 & 7.7398 & -6.9925287 \\
\hline 7.059 & -5.2329539 & 7.4067998 & -6.7613776 & 7.7472 & -7.0033209 \\
\hline 7.0664001 & -5.276091 & 7.4141998 & -6.7745251 & 7.7546 & -7.0149742 \\
\hline 7.0738001 & -5.3192253 & 7.4215999 & -6.7868029 & 7.7620001 & -7.0275203 \\
\hline 7.0812001 & -5.3623255 & 7.4289999 & -6.7982349 & 7.7694001 & -7.0409909 \\
\hline 7.0886002 & -5.4053614 & 7.4363999 & -6.8088438 & 7.7768002 & -7.0554194 \\
\hline 7.0960002 & -5.4483025 & 7.4438 & -6.8186554 & 7.7842002 & -7.0708358 \\
\hline 7.1034002 & -5.4911142 & 7.4512 & -6.8276987 & 7.7916002 & -7.0872724 \\
\hline 7.1107998 & -5.5337659 & 7.4586 & -6.8360023 & 7.79899998 & -7.1047569 \\
\hline 7.1181998 & -5.5762257 & 7.4660001 & -6.8435978 & 7.8063998 & -7.1233207 \\
\hline 7.1255999 & -5.6184576 & 7.4734001 & -6.850517 & 7.8137999 & -7.1429923 \\
\hline 7.1329999 & -5.6604321 & 7.4808002 & -6.8567963 & 7.8211999 & -7.1638 \\
\hline 7.1403999 & -5.7021127 & 7.4882002 & -6.8624694 & 7.8285999 & -7.185771 \\
\hline 7.1478 & -5.7434666 & 7.4956002 & -6.8675732 & 7.836 & -7.2089351 \\
\hline 7.1552 & -5.7844587 & 7.5029998 & -6.8721479 & 7.8434 & -7.2333188 \\
\hline 7.1626 & -5.8250548 & 7.5103998 & -6.8762314 & 7.8508 & -7.2589478 \\
\hline 7.1700001 & -5.86522218 & 7.5177999 & -6.8798626 & 7.8582001 & -7.2858491 \\
\hline 7.1774001 & -5.9049271 & 7.5251999 & -6.8830856 & 7.8656001 & -7.3140485 \\
\hline 7.1848001 & -5.9441363 & 7.5325999 & -6.8859401 & 7.8730001 & -7.3435728 \\
\hline 7.1922002 & -5.9828136 & 7.54 & -6.8884697 & 7.8804002 & -7.37444566 \\
\hline 7.1996002 & -6.0209301 & 7.5474 & -6.8907169 & 7.8878002 & -7.4066936 \\
\hline 7.2069998 & -6.0584515 & 7.5548 & -6.8927242 & 7.8951998 & -7.4403412 \\
\hline 7.2143998 & -6.0953462 & 7.5622001 & -6.8945371 & 7.9025998 & -7.475413 \\
\hline 7.2217999 & -6.1315841 & 7.5696001 & -6.8961992 & 7.90999998 & -7.5119331 \\
\hline 7.2291999 & -6.1671342 & 7.5770001 & -6.8977553 & 7.9173999 & -7.5499264 \\
\hline 7.2365999 & -6.2019691 & 7.5844002 & -6.8992481 & 7.9247999 & -7.5894177 \\
\hline 7.244 & -6.236059 & 7.5918002 & -6.9007249 & 7.9322 & -7.6304296 \\
\hline 7.2514 & -6.2693795 & 7.5991998 & -6.9022273 & 7.9396 & -7.672987 \\
\hline 7.2588 & -6.3019019 & 7.6065998 & -6.9038012 & 7.947 & -7.717114 \\
\hline 7.2662001 & -6.3336051 & 7.6139998 & -6.9054899 & 7.9544001 & -7.7628337 \\
\hline 7.2736001 & -6.3644652 & 7.6213999 & -6.9073368 & 7.9618001 & -7.8101705 \\
\hline 7.2810001 & -6.394462 & 7.6287999 & -6.9093871 & 7.9692001 & -7.8591485 \\
\hline 7.2884002 & -6.4235757 & 7.6362 & -6.9116821 & 7.9766002 & -7.9097917 \\
\hline 7.2958002 & -6.4517886 & 7.6436 & -6.9142657 & 7.9840002 & -7.9621241 \\
\hline 7.3031998 & -6.4790867 & 7.651 & -6.9171794 & 7.9913998 & -8.0161695 \\
\hline 7.3105998 & -6.5054538 & 7.6584001 & -6.9204647 & 7.9987998 & -8.0719525 \\
\hline 7.3179998 & -6.5308804 & 7.6658001 & -6.924164 & 8.0061998 & -8.1294999 \\
\hline 7.3253999 & -6.5553565 & 7.6732001 & -6.9283172 & 8.0136003 & -8.1888329 \\
\hline 7.3327999 & -6.5788749 & 7.6806002 & -6.9329635 & 8.0209999 & -8.2499786 \\
\hline 7.3401999 & -6.6014303 & 7.6880002 & -6.9381449 & 8.0284004 & -8.3129628 \\
\hline
\end{tabular}




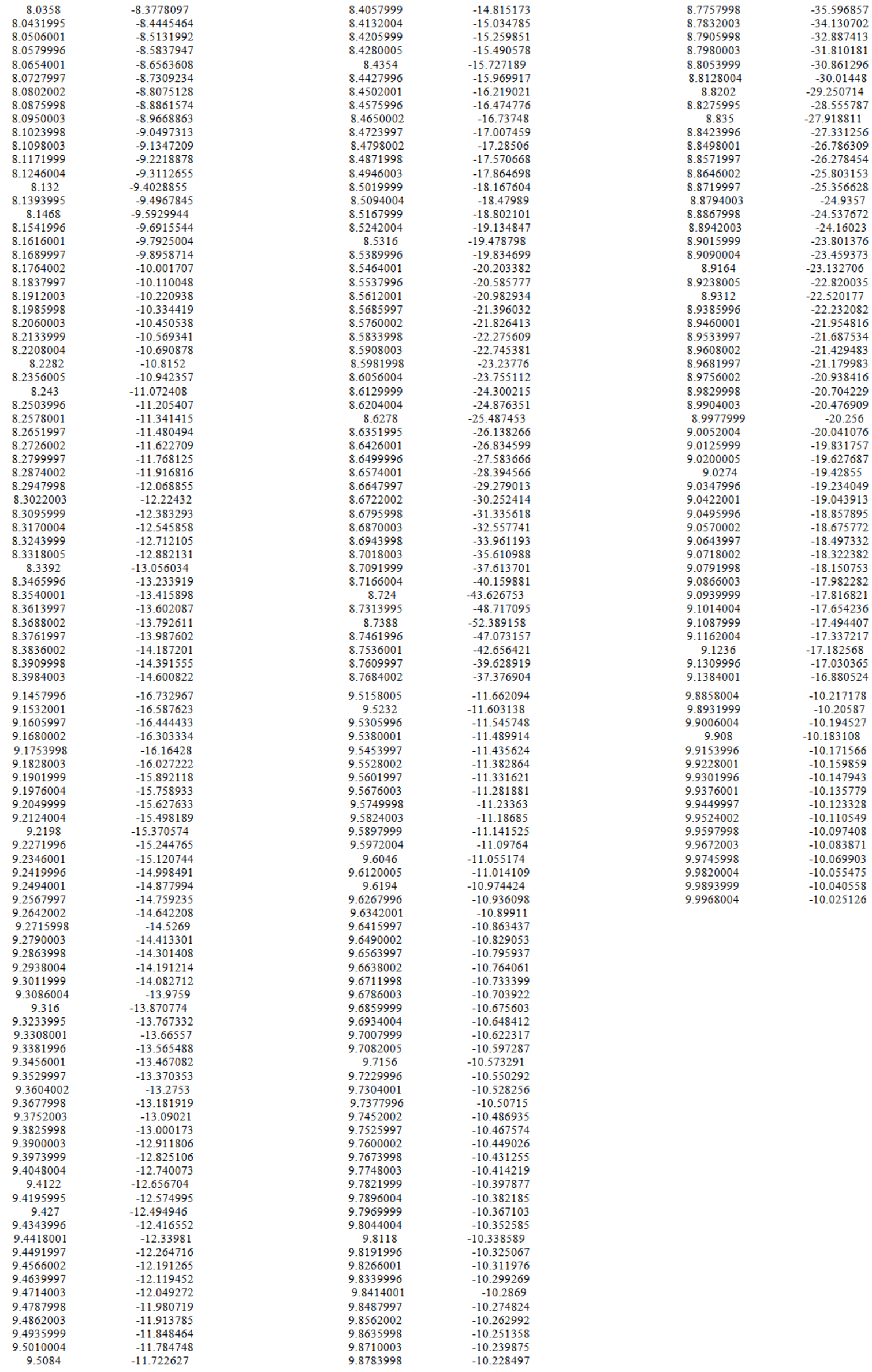

